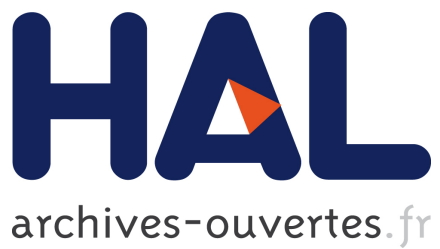

\title{
The Effect of Uncertainty on Pollution Abatement Investments: Measuring Hurdle Rates for Swedish Industry
}

\author{
Åsa Löfgren, Katrin Millock, Céline Nauges
}

\section{To cite this version:}

Åsa Löfgren, Katrin Millock, Céline Nauges. The Effect of Uncertainty on Pollution Abatement Investments: Measuring Hurdle Rates for Swedish Industry. Resource and Energy Economics, Elsevier, 2008, 30 (4), pp.475-491.

HAL Id: halshs-00343702

\section{https://halshs.archives-ouvertes.fr/halshs-00343702}

Submitted on 2 Dec 2008

HAL is a multi-disciplinary open access archive for the deposit and dissemination of scientific research documents, whether they are published or not. The documents may come from teaching and research institutions in France or abroad, or from public or private research centers.
L'archive ouverte pluridisciplinaire HAL, est destinée au dépôt et à la diffusion de documents scientifiques de niveau recherche, publiés ou non, émanant des établissements d'enseignement et de recherche français ou étrangers, des laboratoires publics ou privés. 


\title{
The Effect of Uncertainty on Pollution Abatement Investments: Measuring Hurdle Rates for Swedish Industry*
}

\begin{abstract}
We estimate hurdle rates for firms' investments in pollution abatement technology, using ex post data. The method is based on a structural option value model where the future price of polluting fuel is the major source of uncertainty facing the firm. The empirical procedure is illustrated using a panel of firms from the Swedish pulp and paper industry, and the energy and heating sector, and their sulfur dioxide emissions over the period 2000 to 2003. The results indicate that hurdle rates of investment vary from 2.7 to 3.1 in the pulp and paper industry and from 3.4 to 3.6 in the energy and heating sector depending on econometric specification.
\end{abstract}

JEL codes: C33, D81, O33, Q48, Q53

Keywords: option value, oil price uncertainty, abatement investment, sulfur emissions, pulp and paper industry, energy and heating sector.

*Financial support from Mistra's Climate Policy Research Program (CLIPORE) is gratefully acknowledged. We thank seminar participants at CARE-Université de Rouen, CORE-Université catholique de Louvain, and participants at the Conference on Environment, Innovation, and Performance, held in Grenoble (France) in June 2007, for useful comments on earlier versions of this paper. We also thank two anonymous reviewers for very insightful comments that have improved the paper. 


\section{Introduction}

A polluting firm usually faces a choice between different abatement possibilities ranging from simple end-of-pipe technologies, that reduce emissions at the end of the production line, to highly complex clean technology systems that necessitate production process changes. Engineering studies normally show a range of feasible investment opportunities (with positive net present values), nevertheless, firms do not invest at the predicted level. Several explanations have been advanced to explain this apparent puzzle, including errors in the measurement of costs, heterogeneity in discount rates or, still, market failures (see for example Hausman, 1979; Sutherland, 1991; Jaffe and Stavins, 1994).

Here, we develop a structural approach to measure the impact of uncertainty in the future price of polluting fuel on a firm's decision to invest in abatement technology. The proposed model will assume that the abatement investment is irreversible, since the equipment normally is firm-specific and has little re-sale value. Fuel use is a major source of air pollution and a rational firm facing environmental and energy taxation would normally consider both the pollution impact and any impact on the energy bill in deciding whether to undertake an abatement investment. Previous research on the U.S. steel industry, for example, showed that higher fuel prices had a significant positive impact on the decision to adopt fuel-saving technologies with a potential to reduce pollution (Boyd and Karlson, 1993).

Choice of irreversible investment under uncertainty relates directly to the option value theory (McDonald and Siegel, 1986; Dixit and Pindyck, 1994), which predicts that firms may delay investment because the value of waiting to resolve uncertainty exceeds the value of owning the asset during the waiting period. Several empirical applications of the option value theory of investment have been developed in order to explain the slow adoption of technologies that reduce emissions and the environmental impact of production.11 Most of these use simulation techniques, though, and there are few ex post studies on investment data. The main contribution of this paper is to estimate hurdle rates $2^{2}$ for abatement investments from a

\footnotetext{
${ }^{1}$ We only consider sunk costs of investment and economic uncertainty. Kolstad (1996) and Pindyck (2000, 2002) analyse the more general social trade-off between sunk costs and foregone benefits as well as economic versus ecological uncertainty.

${ }^{2}$ The hurdle rate is the multiplier of the level of the polluting fuel price that triggers the investment according
} 
structural option value model, using ex post data from the Swedish energy and heating sector and pulp and paper industry.

Following Dixit and Pindyck (1994) we derive the threshold condition on the price of the polluting fuel for which a firm facing uncertainty will decide to invest in a new abatement technology. As in Harchaoui and Lasserre (2001), the proposed estimation procedure is based on the fact that this threshold condition holds at the time of the investment. Whereas Harchaoui and Lasserre (2001) provide a test of the option value theory in a more general framework, we instead measure hurdle rates for Swedish abatement investments under the assumption that the real option theory is relevant for all firms in our sample, and we discuss some of the potential policy implications of our results. We propose two approaches to measure hurdle rates: first, through direct computation of individual hurdle rates for each firm that has invested, second, through an econometric estimation that controls for random measurement error. Necessary data are firm characteristic data (such as fuel consumption, input prices, and output) before and after the investment took place as well as information on the actual capital costs of investment. The model is adapted to air pollution from fuel use and the econometric procedure is illustrated using a panel of firms from the Swedish pulp and paper industry, and the energy and heating sector and their $\mathrm{SO}_{2}$ emissions from 2000 to 2003. The Swedish energy and heating sector is the primary fuel-consuming sector in Sweden, representing over 30\% of total fuel consumption (in 2003), but the pulp and paper industry is also a major user of fuels (10\% of total fuel consumption in 2003). Fuel costs on average account for around $20 \%$ of the sales value in the energy and heating sector, and $2 \%$ for the pulp and paper industry, so the model's assumption of the main uncertainty being the one surrounding the future price of polluting fuel is particularly relevant for the energy and heating sector, but is still of relevance for the pulp and paper industry. Over the period studied here, the Swedish pulp and paper industry and the energy and heating sector contributed to a high extent to industrial-source carbon dioxide $\left(\mathrm{CO}_{2}\right)$ emissions, as well as sulfur dioxide $\left(\mathrm{SO}_{2}\right)$ emissions and nitrogen oxides $\left(\mathrm{NO}_{x}\right)$ emissions ${ }^{3}$ The results indicate that the presence of an option value due to uncertainty to a standard net present value calculation.

${ }^{3}$ The pulp and paper industry and the energy and heating sector together accounted for around $50 \%$ of stationary $\mathrm{CO}_{2}$ emissions, $40 \%$ of stationary $\mathrm{SO}_{2}$ emissions and $35 \%$ of stationary $\mathrm{NO}_{x}$ emissions in 2003. 
in the price of polluting fuel would multiply the standard hurdle rate for investment by a factor ranging from 2.7 to 3.1 in the pulp and paper industry, and from 3.4 to 3.6 in the energy and heating industry depending on econometric specification. We suggest future extensions of the model but argue that, although other explanations are possible, firms in these two sectors may delay adoption of irreversible abatement technologies because of uncertainty in the price of polluting fuel. We also find evidence that investment in abatement technologies has not induced a significant decrease in $\mathrm{SO}_{2}$ emissions in any of the two sectors.

We review the existing literature in Section 2. Section 3 presents the theoretical model. The data and background are described in Section 4. The econometric specification and the method we propose are described in Section 5. The estimation results are presented in Section 6, and we discuss some policy implications and suggest future extensions of the model in Section 7.

\section{Abatement Investment Choice under Uncertainty}

In standard investment theory, under certainty, there is no option value and investment is made following the simple Net Present Value (NPV) rule: invest when the present discounted value of the investment equals or exceeds the investment cost. In the option value theory of investment, the fact that investment is irreversible and undertaken under uncertainty leads the firm to consider an additional component in its investment choice, namely the value of waiting to invest. For example, following Dixit and Pindyck (1994), uncertainty on the value of a new technology can be modeled as a geometric Brownian motion. By definition, a Brownian motion is a Markov process, which implies that only current information is useful in forecasting the future path of the process. Hence, this kind of assumption about the form of uncertainty is well suited to financial assets because of the efficient market paradigm. Uncertainty surrounding an investment project can be assumed to follow the same process, since its payoff can be defined as the difference between the firm's discounted stream of profits using the new technology and its discounted stream of profits using the existing technology. Above all, though, the assumption of a Brownian motion allows for an analytical solution to the problem.

The option value theory of investment has led to a rich literature of empirical applications, 
also in environmental policy analysis. In energy policy, Herbelot (1992) used it to study utilities' choice of abating $\mathrm{SO}_{2}$ emissions by installing scrubbers, substituting input or buying tradeable emission permits. Insley (2003) also studied the choice faced by U.S. power plants to install scrubbers to control sulfur emissions, assuming that $\mathrm{SO}_{2}$ permit prices are stochastic and explicitly accounting for the long construction process. She estimated the critical price of tradeable permits that would cause the plant owner to install a scrubber and her results on firm investment behaviour are supported by data from the U.S. experience with sulfur emissions trading. Hassett and Metcalf (1993, 1995a) analyzed residential energy conservation investments assuming that energy prices follow a Brownian motion. The resulting hurdle rate for energy conservation investment (4.23) is about four times higher than the standard hurdle rate when there is no uncertainty. In agricultural policy, Purvis et al. (1995) studied the adoption of free-stall dairy housing with stochastic milk production and feed costs, and found a hurdle rate around 2. Diederen, van Tongeren and van der Veen (2003) studied the adoption of energy saving technologies in Dutch greenhouse horticulture with uncertainty in the energy price and the energy tax and found a hurdle rate of almost twice the rate predicted by net present value calculations. Khanna, Isik and Winter-Nelson (2000) analyzed the adoption of site-specific crop management with stochastic output price and expectations of declining fixed costs of the equipment. When accounting for the option value, it was preferable to delay the investment for at least three years compared to the net present value rule, for most soil quality levels. The value of waiting to adopt this technology also increased the subsidy rates required for immediate adoption. Carey and Zilberman (2002) simulated the adoption of irrigation technology when water price and supply are stochastic, and derived a hurdle rate equal to 2.33.

The bulk of these applications use simulations to study the consequences of uncertainty on irreversible investment. Exceptions are Richards (1996), who analyzes hysteresis in dairy output quota investment and Maynard and Shortle (2001) that study clean technology adoption in paper and pulp mills. Richards (1996) uses a generalized Leontieff value function to derive investment demand equations which are estimated on panel data and which confirm an option value related to investment in dairy quota licences. Maynard and Shortle (2001) use a 
double hurdle rate model as in Dong and Saha (1998) which involves estimating two reduced-form simultaneous equations, one for the expected net present value of the investment, the other one for the negative value of waiting to learn more before investing in a clean technology. The majority of the variables used to proxy the plant's value of waiting with the investment were found to be significant.

The only real test of the option value theory that we are aware of is Harchaoui and Lasserre (2001), who use econometric methods to test whether Canadian copper mines' decisions on capacity are compatible with the notion of a trigger price. Their main objective is not to estimate hurdle rates per se but instead to test whether the actual decisions made by the firms facing irreversible investment choices under uncertainty may be explained by the real option theory. This paper comes closest to ours and we will discuss further the similarities and differences in method below in Section 5. Our main contribution is to present an alternative empirical procedure that allows the measurement of firm- and sectoral hurdle rates on ex post data. In the application presented here, we present the first estimates (to our knowledge) of hurdle rates for pollution abatement investments by Swedish industry.

\section{The Theoretical Model}

We use a theoretical model based on the assumption that emissions derive from inefficient use of a polluting input (Khanna and Zilberman, 1997). Consider a plant using a polluting input (fossil fuel) in its production process. To simplify the analysis, assume the plant produces a single output $q$ from this polluting input only. The polluting input suffers heat losses, and its effective use in production depends on the efficiency of the process. The production function $f$ can therefore be written as a function of useful input with technology $i$,

$e_{i}: q_{i}=f\left(e_{i}\right)$ with decreasing returns in effective input use: $\frac{\partial f}{\partial e}>0$ and $\frac{\partial^{2} f}{\partial e^{2}}<0$. The parameter $h_{i}$ is used to account for efficiency in input use with technology $i$, where $h_{i}$ is the ratio of useful input $\left(e_{i}\right)$ to applied input $\left(a_{i}\right): h_{i}(\theta)=\frac{e_{i}}{a_{i}} \cdot \theta$ captures firms' heterogeneity (firms are heterogenous in that the input use efficiency depends on management or other firm characteristics). Applied input represents the amount of fuel put into the production process, 
whereas effective input is the amount that is effectively used in production, net of heat losses and other inefficiencies. The production function can thus be written $q_{i}=f\left(h_{i}(\theta) a_{i}\right)$. A plant can choose to invest $(i=1)$ or not $(i=0)$ in a new technology that will not reduce input-use efficiency: $h_{1}(\theta) \geq h_{0}(\theta)$. Improvements in blast furnace efficiency is one example. It is assumed that pollution is proportional to applied input: the total amount of emissions $z$ is a constant share $\gamma$ of the applied input. Equivalently, we have the relationship $z_{i}=\gamma_{i} a_{i}$. All else equal, the adoption of a new abatement technology does not increase the pollution coefficient and $\gamma_{1} \leq \gamma_{0}$. This modeling is well adapted to carbon and sulfur emissions from energy use, but constitutes only an approximation of the creation of $\mathrm{NO}_{x}$ emissions ${ }^{4}$

Investing in the new technology implies a fixed cost $\left(I_{1}>0\right.$ and $\left.I_{0}=0\right)$. Plants are assumed to be price-takers both in the input and output markets. $P$ is the unit output price and $m$ the input price. For consistency with the data, we incorporate an emission tax $\tau$ that is to be paid for each unit of emitted pollutant $5^{5}$ At a given time, the private profit function reads $\Pi_{i}\left(a_{i}\right)=\operatorname{Pf}\left(h_{i}(\theta) a_{i}\right)-m a_{i}-\tau \gamma_{i} a_{i}$ and the value of the investment, $v(m)$, is measured by the increase in the profit flow due to the new technology ${ }^{6}$

$$
\begin{aligned}
v(m) & =P\left[f\left(h_{1}(\theta) a_{1}^{*}\right)-f\left(h_{0}(\theta) a_{0}^{*}\right)\right]-\left[\left(m+\tau \gamma_{1}\right) a_{1}^{*}-\left(m+\tau \gamma_{0}\right) a_{0}^{*}\right] \\
& =P \triangle y^{*}-m \triangle a^{*}-\tau \triangle\left(\gamma a^{*}\right)
\end{aligned}
$$

where $\triangle y^{*}=\left[f\left(h_{1}(\theta) a_{1}^{*}\right)-f\left(h_{0}(\theta) a_{0}^{*}\right)\right], \triangle a^{*}=a_{1}^{*}-a_{0}^{*}$, and $\triangle\left(\gamma a^{*}\right)=\gamma_{1} a_{1}^{*}-\gamma_{0} a_{0}^{*}$.

We assume that firms face uncertainty only in the price of polluting fuel, and not in the price of output. The latter assumption appears reasonable for our dataset. Indeed, fuel price variation is known to be far more important than output price variation in the Swedish pulp and paper sector.7 In the electricity spot market where the price is highly volatile, most firms

\footnotetext{
${ }^{4} \mathrm{NO}_{x}$ emissions are largely due to the chemical reaction in the combustion chamber between nitrogen and oxygen from the air. The extent and speed of this reaction is highly nonlinear in temperature and other combustion parameters.

${ }^{5}$ Throughout, we consider a unique type of polluting emissions, $z$. It would be straightforward to extend the model to a vector of polluting emissions.

${ }^{6} \mathrm{As}$ is standard, an asterisk denotes the optimal value of the variable.

${ }^{7}$ Using analysis of variance (ANOVA) on a 12-year series (1993-2004), we can show that the variability in aggregate value added for the pulp and paper sector is almost entirely explained by the variation in the oil price, while the variation in the output price (we use a sectoral index) has a very small contribution. Results from ANOVA are not shown here but are available from the authors upon request.
} 
have contracts for 5-10 years and households can buy electricity on contracts up to three years, that significantly reduces the uncertainty on the output price. We also assume that there is no uncertainty on polluting emissions tax rates, but depending on data availability and the specific case studies, this assumption can be relaxed (see Model Specification and Estimation Procedure Section below for further discussion) 8 The future price of polluting fuel (oil in this case) is assumed to be represented by a geometric Brownian motion with positive drift $\alpha_{m}$ and variance rate $\sigma_{m}$ :

$$
d m=\alpha_{m} m d t+\sigma_{m} m d z_{m} \quad \text { where } d z_{m}=\varepsilon \sqrt{d t}, \varepsilon \sim N(0,1) .
$$

The expected price of polluting fuel thus grows at a constant rate $\alpha_{m}$. Choosing an appropriate process for the uncertain fuel price is a much contended issue. Some tests find that the oil price follows random walks (Berck and Roberts, 1996; Ahrens and Sharma, 1997), others reject the unit root hypothesis on the same data using stronger tests (Lee, List and Strazicich, 2006), although we note that the unit root hypothesis cannot be rejected for petroleum prices when using the most general form of the statistic in Lee, List and Strazicich (2006), a two-break LM unit root test with quadratic trend. The choice of the stochastic process for the fuel price is ultimately an empirical issue. We perform a unit root test on our data and cannot reject the null hypothesis of a random walk, but this may be expected on annual data when the test period is inferior to 100 years (Pindyck, 1999). Even if the unit root test cannot reject the null hypothesis of a random walk, it does not automatically imply that prices follow a geometric Brownian motion. Nevertheless, we choose to use this assumption, since it gives us an analytical closed form solution. It is a weakness of the current model and future research may improve the model by studying the robustness to alternative assumptions on the stochastic process of the polluting fuel price using simulations as in Harchaoui and Lasserre (2001) or Isik (2006) 9

\footnotetext{
${ }^{8}$ For models of policy uncertainty, see Larson and Frisvold (1996) for an analysis of tax uncertainty, and Isik (2004) for an analysis of uncertainty surrounding a cost-share subsidy and its impact on technology adoption.

${ }^{9}$ Sarkar (2003) concedes that Hassett and Metcalf's (1995b) arguments that a geometric Brownian motion may be a reasonable approximation (even if the real process is one of mean reversion) may hold for low volatility processes. Over the time length of an abatement investment, Postali and Picchetti (2006) argue that the low speed of mean reversion in oil prices also may imply low estimation errors from using a geometric Brownian motion instead.
} 
We start by describing the investment choice when there is no uncertainty $\left(\sigma_{m}=0\right)$. The present discounted value (at the time of the investment, $T$ ) of the increase in profit flows over all future time periods is:

$$
V(m)=\int_{T}^{\infty}\left[P \triangle y^{*}-m_{T} e^{\alpha_{m}(t-T)} \triangle a^{*}-\tau \triangle\left(\gamma a^{*}\right)\right] e^{-\rho(t-T)} d t
$$

where $\rho$ is the appropriate discount rate. The present value can be written

$$
V(m)=\frac{P \triangle y^{*}}{\rho}-\frac{m_{T} \triangle a^{*}}{\delta}-\frac{\tau \triangle\left(\gamma a^{*}\right)}{\rho}
$$

where $\delta=\rho-\alpha_{m}$. The parameter $\delta$ is defined as the difference between the firm's cost of capital and the drift rate of the price of polluting fuel. It is necessary to assume that the discount rate exceeds the drift in the polluting fuel price in order for the option to invest to be exercised. The data we use confirm this assumption (the drift rate is estimated at 0.0240 and $\rho$ is around 20\%).

The present value of the investment depends on the price of polluting fuel through the term $\left(\frac{m_{T} \triangle a^{*}}{\delta}\right)$. Given that $\delta$ is positive, $V(m)$ is an increasing [decreasing] function in the polluting fuel price when polluting fuel input use decreases [increases] following the investment. In the first case, an increase in the price of polluting fuel leads to an increase in the present value of investment, whereas in the second case, it is a decrease in the price of polluting fuel that will increase the present discounted value of the project.

Without any uncertainty, the firm would invest when the expected present discounted value of the investment exceeds the cost of the investment, here assumed constant, i.e., if $V(m) \geq I$ which is equivalent to a trigger price for investment, $m_{T}=\bar{m}$, equal to

$$
\bar{m}=\frac{\delta}{\triangle a^{*}}\left(-I+\frac{P \triangle y^{*}}{\rho}-\frac{\tau \triangle\left(\gamma a^{*}\right)}{\rho}\right) .
$$

All else equal, if $\triangle a^{*}>0$ (i.e. polluting fuel consumption is higher with the new technology) then investment will be valuable if the price of polluting fuel is less than or equal 
to $\bar{m}$. If $\triangle a^{*}<0$ (i.e. polluting fuel consumption is lower with the new technology) then investment will be valuable if the price of polluting fuel is greater than or equal to $\bar{m}$.

Let us now compare the investment decision under the NPV rule with the investment decision when the uncertainty around the future price of polluting fuel is taken into account. The new investment threshold can be derived following Dixit and Pindyck (1994). A new term, called the hurdle rate (here $\beta_{1} /\left(\beta_{1}-1\right)$ ), enters the equation. The hurdle rate is the multiplier of the level of the polluting fuel price that triggers the investment according to a standard net present value calculation. The trigger price for investment changes to $\tilde{m}$ (derivation in Appendix):

$$
\tilde{m}=\left(\frac{\beta_{1}}{\beta_{1}-1}\right) \times A \quad \text { where } \quad A=\frac{\delta}{\triangle a^{*}}\left(-I+\frac{P \triangle y^{*}}{\rho}-\frac{\tau \triangle\left(\gamma a^{*}\right)}{\rho}\right) \text { and } \frac{\beta_{1}}{\beta_{1}-1} \geq 1
$$

If $\triangle a^{*}>0$ then investment will be valuable if the price of polluting fuel is less than or equal to the new trigger price $\tilde{m}$, whereas if $\triangle a^{*}<0$ (i.e. polluting fuel consumption is lower with the new technology) then investment will be valuable if the price of polluting fuel exceeds or equals $\tilde{m}$.

This new trigger value for investment depends on a term based on the discount rate and the parameters of the stochastic process:

$$
\beta_{1}=\frac{1}{2}-\frac{\alpha_{m}}{\sigma_{m}^{2}}+\sqrt{\left[\frac{\alpha_{m}}{\sigma_{m}^{2}}-\frac{1}{2}\right]^{2}+\frac{2 \rho}{\sigma_{m}^{2}}} .
$$

A comparison of the two trigger prices for investment (Equations 4 and 5) shows that irreversibility and uncertainty imply that the polluting fuel price has to be multiplied with $\beta_{1} /\left(\beta_{1}-1\right)$ for investment to take place in the case when the new technology leads to a reduction in polluting fuel consumption.

\section{Background and Data}

For the purpose of this paper, we consider firms belonging to the pulp and paper industry and the energy and heating sector, for which fuels are crucial inputs in the production process. Our data set is an unbalanced panel over the 2000-2003 period of 58 firms from the pulp and paper 
industry and 15 firms from the energy and heating sector. Data on firms' investment in air pollution abatement technology are collected by Statistics Sweden. This agency has administered the statistics on investment in air pollution abatement since 1981. The quality and method has changed over time, though, and comparable data is available only from 1999. Statistics Sweden's survey includes firms in the manufacturing industry and the energy and heating sector with more than 20 employees. Samples of roughly 1,000 firms are drawn from a population of 4,500 firms, and firms with more than 250 employees are surveyed each year. The firm ID numbers allow to match the existing firm-level data with business data, such as revenue (i.e., income received from the sales of goods), value added, labor, and data on fuel consumption and fuel prices at the firm-level. More specifically, we have information on firms' consumption and purchases of 12 different types of fuels (among them oil, coal, coke, natural gas and different types of biofuel) as well as the annual average price of each fuel. From these data, we compute an annual average weighted price of polluting fuel for each firm (in EUR per TJ).

The price of fuel includes all relevant taxes, among which the energy tax, the taxes on $\mathrm{CO}_{2}$ and sulfur emissions and the $\mathrm{NO}_{x}$ fee are the most important 10 The use of prices including taxes has implications regarding the specification and estimation of the equation of interest (5), which is discussed further below in the Model Specification and Estimation Procedure Section.

Table 1 presents descriptive statistics of the overall sample. Over the period covered by the data, there were 84 decisions (68 in the pulp and paper industry and 16 in the energy and heating sector) by 47 different firms (36 firms in the pulp and paper industry and 11 firms in the energy and heating sector) to invest in abatement technology among the 73 firms. Investments in our sample either belong to the end-of-pipe category (for example filters, scrubbers and centrifuges) or to the clean technology category (above all equipment allowing a switch to less polluting raw materials and fuels). In the empirical application, the method will be illustrated

\footnotetext{
${ }^{10}$ The $\mathrm{CO}_{2}$ tax varied during 2000-2003. The yearly levels are available from the Swedish Energy Agency for each polluting fuel. As an example the $\mathrm{CO}_{2}$ tax for oil was: $1,058 \mathrm{SEK} / \mathrm{m}^{3}$ in $2000,1,527 \mathrm{SEK} / \mathrm{m}^{3}$ in $2001,1,798$ $\mathrm{SEK} / \mathrm{m}^{3}$ in 2002 , and $2,174 \mathrm{SEK} / \mathrm{m}^{3}$ in 2003. Energy and $\mathrm{CO}_{2}$ taxes are levied on fossil fuels such as oil, coal, coke and natural gas while biofuels are in general exempt from energy tax. Firms pay the sulfur tax in relation to the fuel used and sulfur content and the $\mathrm{NO}_{x}$ fee is based on emitted $\mathrm{NO}_{x}$ but it is refunded back to firms in relation to production. In 2003 the total $\mathrm{CO}_{2}$ tax payment in the pulp and paper sector was 45 million EUR, which can be compared to the total energy tax of 4.5 million EUR and the total sulfur tax paid by the sector of 2 million EUR. Corresponding figures for the energy and heating sector are 143 million EUR in total $\mathrm{CO}_{2}$ tax, 31 million EUR in total energy tax and 14.5 million EUR in total sulfur tax (Statistics Sweden).
} 
on investments in abatement technologies affecting $\mathrm{SO}_{2}$ emissions. Table 2 provides the average characteristics of firms that invested and firms that did not invest in abatement technology. As expected, the firms that invested run more fuel-intensive production processes, and their average fuel cost is higher. Those firms also have on average higher $\mathrm{SO}_{2}$ emissions.

\section{Model Specification and Estimation Procedure}

As in Harchaoui and Lasserre (2001), we build our econometric model on the following result: under the assumption that the option value model is a correct representation of firms' choices, Equation (5) specifying the threshold price necessarily holds at the time when the firm undertakes the investment. Because the price of polluting fuel includes emission taxes in our data, Equation (5) simplifies to:

$$
\tilde{m}=\left(\frac{\beta_{1}}{\beta_{1}-1}\right) \times A \text { where } A \text { is now equal to } \frac{\delta}{\triangle a^{*}}\left(-I+\frac{P \triangle y^{*}}{\rho}\right),
$$

and $\tilde{m}$ is the price of polluting fuel including emission taxes ${ }^{11}$ This specification remains valid as long as we assume that there is no change in the emission coefficient, $\gamma=\bar{\gamma}$ (see Appendix). This assumption holds only for clean technology investments, where emissions decrease only because of increased efficiency in input use 12

In Equation (7), the price of polluting fuel, $\tilde{m}$, is observed. We propose to estimate the right-hand-side term $A$ using observed data from the firm (see below for further details). Once we have an estimate of $A$, let us call it $\widehat{A}$, the only unknown in Equation 77 is the hurdle rate, $\beta_{1} /\left(\beta_{1}-1\right)$, that we propose to measure using two different approaches. The first approach is to consider that Equation (7) is deterministic, which allows the direct computation of the hurdle rate for each firm $j$ which has invested in clean technology at time $t$ :

$$
b_{j t}=\tilde{m}_{j t} \times \widehat{A}^{-1} .
$$

\footnotetext{
${ }^{11}$ An artifact from this simplified version, where the price of polluting fuel includes emission taxes, is that we have a combination of price and policy uncertainty. That is, the hurdle rate is a measure of the uncertainty in the polluting fuel price including taxes.

${ }^{12}$ In terms of the theoretical model, $h_{1}>h_{0}$ and $\gamma_{1}=\gamma_{0}=\bar{\gamma}$.
} 
The second approach consists in estimating Equation (7) in which an error term has been appended (in order to control for random measurement error), on the sub-sample of firms $j$ that have invested in clean technology at time $t$. By applying Ordinary Least Squares (OLS) on the model:

$$
\tilde{m}_{j t}=b \times \widehat{A}+u_{j t}
$$

we get a consistent estimate of $b$ under the assumption that $u$ is uncorrelated with $\widehat{A}$. In this particular case without any constant term in Equation (9), the OLS estimator of $b$ corresponds to the sample mean of $b_{j t}$. On the one hand, this approach does not allow to get firm-specific hurdle rates but, on the other hand, it allows to test whether the (average) hurdle rate is significantly different from 1 with a simple Fisher-test. The drawback though is that, because the OLS equation contains generated regressors, the standard error of the estimated hurdle rate is likely to be computed with error (Pagan, 1984). The computation of the efficient second-stage standard error would be complicated in this particular case, and is outside the scope of this paper.

Both approaches are applied to the sub-sample of firms that invested in clean technology during the period covered by the data, using the observed variables in the year the investment took place. We describe below the procedure to estimate term $A$ in Equation (7). The proposed estimation procedure requires the following set of data:

- $\delta=\rho-\alpha_{m}$, in our case the difference between the firm's cost of capital and the positive drift rate of the price of polluting fuel. The drift rate of the fuel price can be calculated by testing for, and then fitting, a Brownian motion to a long time series of fuel price data (in our case the fuel price including tax) 13

- $I$, the total investment cost.

- $\triangle a^{*}$, i.e., the difference between polluting fuel use with the new technology compared to polluting fuel use if the old technology were still in place at the time of investment. We observe polluting fuel consumption in the year when the new technology was adopted $\left(a_{1}^{*}\right)$,

\footnotetext{
${ }^{13}$ If historical fuel price data are not available at the firm level, one can use national fuel price data instead.
} 
but do not know what the polluting fuel use would have been if the firm had not invested in the new technology $\left(a_{0}^{*}\right)$. The latter can be predicted, though, from the data as long as some firms invested during the period of observation. The impact of the investment decision on fuel use can be derived from the estimation of a model fitting polluting fuel use, using the whole sample of firms. The coefficient of the investment decision indicator in combination with the data from the year when the firm has adopted the new technology enables us to predict the polluting fuel consumption if the firm had not invested in the new technology, $\hat{a}_{0}^{*}$.

- Likewise, $\triangle y^{*}$ represents the difference between output level with the new technology and with the old technology. We will follow the same procedure as for predicting the difference in polluting fuel use, using the estimated coefficient of the investment decision indicator in a model fitting output 14

In our application, it is not necessary to estimate the change in polluting emissions after the investment took place since emission taxes are included in the price of fuel (and hence the change in emissions does not show in the right-hand-side term of Equation (7)). However, we propose to consider an equation fitting polluting emissions in order to test for the impact of the new technology on pollution in the two sectors.

More efficient parameter estimates will be obtained by estimating a system of equations fitting simultaneously polluting fuel use, polluting emissions, and output. A general form of the system is:

$$
\left\{\begin{array}{l}
a_{j t}=a\left(X_{1 j t}^{\prime}, c_{1}\right)+\varepsilon_{1 j t} \\
z_{j t}=z\left(X_{2 j t}^{\prime}, c_{2}\right)+\varepsilon_{2 j t} \\
y_{j t}=y\left(X_{3 j t}^{\prime}, c_{3}\right)+\varepsilon_{3 j t}
\end{array}\right.
$$

where $j$ and $t$ are respectively the index for firm and year, $a(),. z($.$) and y($.$) are unknown$ functions and $c_{k}(k=1,2,3)$ are vectors of parameters to be estimated. The sets of explanatory factors $\left(X_{k j t}, k=1,2,3\right)$ include a variable measuring the total amount of the (clean-technology)

\footnotetext{
${ }^{14}$ If the data contain information on revenue $\left(P y^{*}\right)$ only and not on output separately $\left(y^{*}\right)$, then $\triangle\left(P y^{*}\right)$ can be estimated in place of $P \triangle y^{*}$.
} 
investment by firm $j$ in year $t$. The usual idiosyncratic error term, $\varepsilon_{k j t}(k=1,2,3)$, is assumed of mean 0. Because it may be correlated across equations (i.e. $\left.E\left(\varepsilon_{k j t} \varepsilon_{k^{\prime} j t}\right) \neq 0 \quad \forall k, k^{\prime}\right)$, a three-stage-least squares (3SLS) estimator is recommended.

The only parameter of interest at this stage is the estimated coefficient of the investment variable in each equation. This parameter is used to compute the predicted changes in polluting fuel consumption, $\widehat{\triangle a^{*}}$, and output, $\widehat{\triangle y^{*}}$. To make it clear, let us describe how we compute the predicted difference in polluting fuel use for firm $j$ that adopted a new abatement technology in year $t-1$. In year $t$, polluting fuel consumption with the new technology, $a_{j t 1}^{*}$, is observed. We predict the change in polluting fuel use with and without the new technology, $\widehat{\triangle a_{j t}^{*}}$, as follows:

$$
\widehat{\triangle a_{j t}^{*}}=\frac{\partial a\left(X_{1 j t}^{\prime}, \hat{c}_{1}\right)}{\partial I_{j t}} I_{j t}
$$

The same procedure is applied to compute the predicted changes in output, $\widehat{\triangle y_{j t}^{*}}$.

Our methodology differs from Harchaoui and Lasserre (2001): in their test of the option value theory of investment, these authors calculate the hurdle rate $\beta_{1} /\left(\beta_{1}-1\right)$ using Equation (6)

$$
\beta_{1}=\frac{1}{2}-\frac{\alpha_{m}}{\sigma_{m}^{2}}+\sqrt{\left[\frac{\alpha_{m}}{\sigma_{m}^{2}}-\frac{1}{2}\right]^{2}+\frac{2 \rho}{\sigma_{m}^{2}}},
$$

and test whether the coefficient of this term equals one in a log-log specification under which the uncertain price is regressed on the hurdle rate and all other variables in the theoretical equation (capacity choice, discount factors, etc.). If Harchaoui and Lasserre (2001) primarily provides a test for the real option theory in a more general framework, we instead measure hurdle rates under the assumption that the real option theory is relevant for all firms in our sample.

\section{Estimation Results}

\subsection{First stage: estimation of the system of simultaneous equations}

We retain a two-equation system, fitting polluting fuel consumption and $\mathrm{SO}_{2}$ emissions 15 We thus abstract from input substitution. While recognizing the importance of substitution

\footnotetext{
${ }^{15}$ The equation fitting output (we used revenue since we do not observe output in our data) was removed from the system because of its low fit. This result may not be surprising, though, since investment in air pollution abatement represents on average a very small share of firms' total investments (between 5-10\% of total gross investments in 1999-2002, SCB 2004).
} 
between polluting fuel and biofuel in our application, we chose to keep the theoretical model simple (i.e. one input) and use an empirical estimation that is coherent with the theoretical model. We do use total fuel consumption in the estimation of $\mathrm{SO}_{2}$ emissions in order to control for all energy use. In the absence of theoretical guidance and in order to control for the robustness of our estimates, several systems (combining different equations with different functional forms and sets of explanatory variables) have been estimated. We report estimated coefficients and corresponding standard errors obtained from the estimation of the three best fitted systems, including different sets of explanatory variables combining the price of labor, the price of polluting fuel, the firm's revenue, and number of employees, either in linear or quadratic form. The main variable of interest is pollution abatement investment. The investment variable is lagged one year in order to avoid endogeneity bias. Specification tests have shown that the coefficient of the investment variable is not equal between the two sectors and is not the same between the two types of investment (clean technology and end-of-pipe). We thus allow for sector-specific coefficients for each type of investment (clean technology and end-of-pipe), which amounts to four different coefficients to be estimated in each equation of the system. We also incorporate unobserved firm-specific effects, $\eta_{k j}(k=1,2)$, that are assumed to be fixed parameters that enter additively in each equation. To control for any correlation between the firm-specific unobservable effect, $\eta_{k j}$, and the explanatory variables, we estimate the system using three-stage least squares (3SLS) on the equations where the Within transformation has been applied ${ }^{16}$ The Within transformation eliminates the firm-specific effects, $\eta_{k j}(k=1,2)$, and the resulting 3SLS estimator is thus robust to any form of correlation between the firm-specific effects and the explanatory variables. We report the 3SLS estimation results of the three systems in Table 3.

The three systems provide very similar results, in particular regarding the sign and magnitude of the estimated coefficients, which allows us to feel confident about the robustness of these estimates. The results confirm some typical ex ante hypotheses on fuel use and emissions: polluting fuel use is found to decrease when its own price increases. Our results also

\footnotetext{
${ }^{16}$ The Within operator transforms each variable in deviation from its mean over the period: in place of any variable $x_{j t}$ in the model, we use $x_{j t}-\bar{x}_{j}$ where $\bar{x}_{j}=1 / T_{j} \sum_{t=1}^{T_{j}} x_{j t}, T_{j}$ being the number of years firm $j$ is observed in the sample.
} 
confirm that a higher fuel consumption translates into higher polluting emissions $\left(\mathrm{SO}_{2}\right.$ emissions here). The coefficients of interest at this stage are the coefficients of the investment variable, and we distinguish between investments made in clean technology and end-of-pipe solutions. We find that investing in clean technology has significantly decreased the consumption of polluting fuel in the energy and heating sector, while investments in end-of-pipe solutions have (significantly) decreased the consumption of polluting fuel in the pulp and paper sector. The negative effect of end-of-pipe investment in the pulp and paper sector might seem non-intuitive at first. However, investments in end-of-pipe solutions, such as measurement equipment, can affect firms' use of polluting input negatively (EUROSTAT's definition of end-of-pipe investments include measurement equipment). By installing such equipment firms get clearer and more reliable emissions data and hence also better information on their energy use, which creates incentives to become more energy efficient. As for the effect of investments on emissions, it is close to zero. If we retain the 10 percent level of significance, we only find evidence of a small but significant effect of the investment in end-of-pipe technologies in the pulp and paper sector on $\mathrm{SO}_{2}$ emissions. The negligible effect of end-of pipe investment on $\mathrm{SO}_{2}$ emissions is probably due to the fact that the sulfur content of most oils today is already quite low. The large reduction of sulfur content was made in the first years after the introduction of the sulfur tax in 1991 (Hammar and Löfgren, 2001) and hence abatement investments have a marginal impact today. For example, the current low sulfur content of oils makes the effect of either switching to cleaner fuels or using a scrubber less effective in reducing emissions.

\subsection{Second stage: computation and estimation of hurdle rates}

Using the estimated coefficients of the three systems estimated in the first stage, we compute the predicted differences in polluting fuel use $\widehat{\triangle a^{*}}$. In order to get an estimate of term $A$ in Equation (7), we also need a measure of $\delta$, which is defined as the difference between the risk-adjusted discount rate $\rho$, and $\alpha_{m}$, the drift in the price of polluting fuel. Estimates of $\rho$ are computed using the standard formula for the weighted average cost of capital (WACC) on sector-specific data on economic/business indicators (source: Statistics Sweden) 17 Because

\footnotetext{
${ }^{17} \mathrm{WACC}=$ debt $/($ debt + equity $) *$ debt rate* $(1$-corporate tax $)+$ equity $/($ debt + equity $) *$ rate of return on own capital.
} 
information on economic indicators were only available by quartile, we were only able to derive an upper bound of the rate of return. This upper bound was estimated at 0.237. In what follows we will test the sensitivity of our results to various levels of the rate of return. $\alpha_{m}$ is estimated using the method proposed by Slade (1988) (see also Harchaoui and Lasserre, 2001). We use annual data on oil prices (including taxes) over the 1980-1999 period (source: OECD) ${ }^{18}$ The geometric Brownian motion is approximated by

$$
\triangle m_{t}=\alpha m_{t}+\nu_{t}, \quad t=1, \ldots, T
$$

where $\nu_{t}=\sigma m_{t} \omega$ is heteroscedastic. The null hypothesis of a random walk cannot be rejected on our data. The estimated $\alpha(0.0240)$ is used as a proxy for $\alpha_{m}$.

Under the assumption that the relationship in Equation (7) is deterministic, we can compute the hurdle rate directly for each of the 61 investment decisions in clean technology, using observations at the time of investment. In Table 4, we report some basic statistics on the distribution of hurdle rates in each of the two sectors. The distribution of hurdle rates is found quite similar between the three models. The sample mean of the computed hurdle rates varies from 2.7 to 3.1 in the pulp and paper industry, and from 3.4 to 3.6 in the energy sector. In all cases, the median is lower than the mean. The range of computed hurdle rates seems reasonable, almost always in the range 1 to 8 . Only for four observations is the hurdle rate found lower than one, even if not very different from one. We also find evidence that the hurdle rate is negatively correlated to a firm's revenue (this correlation is significantly different from 0 ), in both sectors. In other words, firms with higher revenues would delay less their adoption decision because of input price uncertainty than firms with lower revenues. Finally, our results show that firms that have invested more than once over the period covered by the data have a lower hurdle rate, on average, than firms that have invested only once. Very little research has been done on the importance of investment frequency for hurdle rates. One exception is Bethuyne (2002) that compares a single-shot investment with multiple technology switches. His results indicate that any bias introduced from underestimating the investment opportunities is more important the smaller are the switching costs relative to operating costs (the opposite of

\footnotetext{
${ }^{18}$ Historically in Sweden, oil and natural gas prices (oil and gas are the two main fossil fuels) have covaried. Hence, the oil price seems an appropriate proxy for the price of polluting energy in this country.
} 
the abatement investments analyzed here). This would be an important area for future research.

We report in Table 5 the estimated coefficient and standard error of the hurdle rate along with the $95 \%$ confidence interval, as obtained from the application of OLS on model (9). The overall fit of the three models is quite high, around 0.8. The estimated hurdle rate corresponds to the sample mean as shown in Table 4. As discussed earlier, because this procedure involves generated regressors, standard errors should be corrected. Nevertheless we use these estimates to compute Fisher-tests. These tests indicate that the estimated hurdle rates are in all cases significantly greater than 1 (at the 1 percent level). The $95 \%$ confidence intervals obtained with the three models overlap, which confirms the robustness of our set of estimates.

Hence, under the assumption that the option value theory applies in this context and that our models are correctly specified, our results indicate that firms in the pulp and paper industry and energy and heating sector have delayed their abatement investment decisions over the 2000-2003 period because of uncertainty on the future price of polluting fuel (including taxes). The hurdle rates that have been obtained conform to theory (they are greater than one) and they are in the range of what has been found in previous studies (based on simulation methods): 4.23 (Hassett and Metcalf, 1993), 2.28 (Purvis et al., 1995), and 2.33 (Carey and Zilberman, 2002). These figures are not fully comparable to ours, though, as they were derived from simulation studies, and were concerned with different countries, sectors, and sources of the main uncertainty facing the firm.

We conclude by a sensitivity analysis of the hurdle rate estimates to the cost of capital, $\rho$. Because the cost of capital that we used could be considered as an upper bound for the Swedish industry, we test how the hurdle rate estimates would change with lower costs of capital. We re-estimate the model in two cases: in the first case $\rho$ is assumed lower by 10 percent $(\rho=0.213)$, and in the second case $\rho$ is assumed lower by 20 percent $(\rho=0.190)$. As predicted by the theoretical model, a decrease in the cost of capital increases the estimated hurdle rates (see Table 6). 


\section{Conclusions and Policy Implications}

The lack of hurdle rate estimates for pollution abatement investments together with the increased availability of data from firms surveyed over several periods of time call for the development of empirical approaches based on observed data. We have computed hurdle rates for abatement investments linked to an option value from irreversible investment when there is uncertainty on the future price of polluting fuel. We proposed two approaches to measure hurdle rates using data from before and after the investment decision. First, through a direct computation of individual hurdle rates for each firm that has invested. Second, through an econometric estimation of sector-specific hurdle rates that controls for random measurement error. We illustrated the method on a panel of firms from the Swedish energy and heating and pulp and paper industry, and their $\mathrm{SO}_{2}$ emissions. The null hypothesis of firms following a NPV rule is rejected as we find that estimated and computed hurdle rates vary from 2.7 to 3.1 for the pulp and paper industry and from 3.4 to 3.6 in the energy and heating industry. We discuss some limitations of the model below, but argue that, although other explanations are possible, firms in these two sectors may thus delay adoption of irreversible abatement technologies because of uncertainty in the price of polluting fuel. The hurdle rate values in the energy and heating industry are significantly higher than those found for the pulp and paper industry, which may be a reflection of the higher relative part of energy costs over sales value for that industry. Uncertainty in the energy price would thus matter more for this industry.

In an intermediate stage, we estimated the impact of investments on consumption of polluting fuel. End-of-pipe investments decreased the use of polluting fuel in the pulp and paper industry while clean technology investments decreased polluting fuel use in the energy and heating sector. We could not find any significant reduction in $\mathrm{SO}_{2}$ emissions from the abatement investments in our sample, the only significant effect being a slight decrease in $\mathrm{SO}_{2}$ emissions from investments in end-of-pipe abatement in the paper and pulp industry. Gaining a better understanding of abatement decisions within fuel-intensive sectors like the energy and heating and pulp and paper industry is important, since these sectors are not only important sources of $\mathrm{SO}_{2}$ emissions, but also of $\mathrm{CO}_{2}$ and $\mathrm{NO}_{x}$ emissions. As for sulfur emissions, the 
Swedish national goal is to reduce emissions to 50,000 ton by 2010 compared to 1990 . When taking into account the Swedish Environmental Protection Agency's (SEPA) projection for changes in the composition of final demand, Östblom (2007) shows that the goal for 2010 may only be attained if economic activity is assumed to be much less emission intensive than in 2000. The negligible effect that we found of end-of pipe investment on $\mathrm{SO}_{2}$ emissions is probably due to the fact that the sulfur content of most oils today is already quite low. The large reduction of sulfur content was made in the first years after the introduction of the sulfur tax in 1991 (Hammar and Löfgren, 2001) and hence abatement investments have a marginal impact today. This implies that further reductions in $\mathrm{SO}_{2}$ emissions may have to be obtained in other sectors. Since the proposed model is based on uncertainty on the future price of polluting fuel, it would be suited to apply for further study on investment in air pollution emission reduction in other sectors as well. The proposed method could hopefully provide insights into the potential for policy measures to reduce sulfur emissions as well as other air pollutants.

One limitation of our study was that we could not include variable costs of abatement investments, nor depreciation costs, in the model since the data were not available. A relevant extension of the current model would be to test the robustness of its conclusions if fuel prices are assumed to follow a mean reversion process instead. Future extensions could further include additional aspects of uncertainty related to irreversible abatement investment, in particular the future cost of investment. If pollution-reducing technology becomes cheaper over time, then an additional explanation for firms delaying investment could be the expected gain from a fall in the investment cost. Issues related to research and development of the new technology were also absent from our analysis ${ }^{19}$ An issue outside the current model concerns the possibility of multiple investment opportunities. We tested for differences in hurdle rates between firms that had invested more than once and those that had made single investments and found a significant difference in hurdle rates. Extending the model to allow for multiple technology switches would constitute an important issue for future research.

\footnotetext{
${ }^{19}$ Even if the new technology is valuable, its arrival date could be uncertain. In this case, van Soest and Bulte (2001) have shown that the option value related to waiting for an even better technology makes the impact on the adoption lag ambiguous.
} 


\section{References}

Ahrens, W.A., Sharma, V.R., 1997. Trends in Natural Resource Commodity Prices:

Deterministic or Stochastic? Journal of Environmental Economics and Management 33, 59-74.

Berck, P., Roberts, M., 1996. Natural Resource Prices: Will They Ever Turn Up?. Journal of Environmental Economics and Management 31(1), 65-78.

Bethuyne, G., 2002. The Timing of Technology Adoption by a Cost-minimizing Firm. Journal of Economics 76(2), 123-154.

Boyd, G.A., Karlson, S.H., 1993. The Impact of Energy Prices on Technology Choice in the United States Steel Industry. The Energy Journal 14(2), 47-56.

Carey, J.M., Zilberman, D., 2002. A Model of Investment under Uncertainty: Modern Irrigation Technology and Emerging Markets in Water. American Journal of Agricultural Economics 84(1), 171-183.

Diederen, F., van Tongeren, F., van der Veen, H., 2003. Returns on Investments in Energy-Saving Technologies Under Energy Price Uncertainty in the Dutch Greenhouse Horticulture. Environmental and Resource Economics 24(4), 379-394.

Dixit, A.K., Pindyck, R.S., 1994. Investment Under Uncertainty, Princeton N.J.: Princeton University Press.

Dong, D., Saha, A., 1998. He Came, He Saw, (and) He Waited: An Empirical Analysis of Inertia in Technology Adoption. Applied Economics 30, 893-905.

Eurostat, 2005. Environmental protection expenditure by industry in the European Union, Statistics in focus, Environment and Energy, 9/2005.

Hammar, H., Löfgren, A. 2001. The Determinants of Sulfur Emissions from Oil Consumption in Swedish Manufacturing Industry, 1976-1995. The Energy Journal 22(2), 107-126.

Harchaoui, T.M., Lasserre, P., 2001. Testing the Option Value Theory of Irreversible Investment. International Economic Review 42(1), 141-66. 
Hassett K.A., Metcalf G.E., 1993. Energy Conservation Investment: Do Consumers Discount the Future Correctly?. Energy Policy 21(6), June, 710-716.

Hassett, K.A., Metcalf, G.E., 1995a. Energy Tax Credits and Residential Conservation Investment: Evidence from Panel Data. Journal of Public Economics 57, 201-217.

Hassett, K.A., Metcalf, G.E., 1995b. Investment under Alternative Return Assumptions:

Comparing Random Walks and Mean Reversion. Journal of Economic Dynamics and Control $19,1471-1488$.

Hausman, J., 1979. Individual Discount Rates and the Purchase and Utilization of Energy-Using Durables. Bell Journal of Economics 10, 33-54.

Herbelot, O., 1992. Optimal Valuation of Flexible Investments: The Case of Environmental Investments in the Electric Power Industry, Unpublished Ph.D. Dissertation, Massachusetts Institute of Technology.

Insley, M. 2003. On the Option to Invest in Pollution Control under a Regime of Tradable Emissions Allowances. Canadian Journal of Economics 36(4), 860-883.

Isik, M. 2004. Incentives for Technology Adoption under Environmental Policy Uncertainty: Implications for Green Payment Programs. Environmental and Resource Economics 27(3), 247-263.

Isik, M. 2006. Implications of Alternative Stochastic Processes for Investment in Agricultural Technologies. Applied Economics Letters 13, 21-27.

Jaffe, A.B., Stavins, R.N., 1994. The Energy-efficiency Gap. What Does it Mean?. Energy Policy 22(10), 804-811.

Khanna, M., Zilberman, D., 1997. Incentives, Precision Technology and Environmental Protection. Ecological Economics, 23(1), 25-43.

Khanna, M., Isik, M., Winter-Nelson, A., 2000. Investment in Site-Specific Crop Management under Uncertainty: Implications for Nitrogen Pollution Control and Environmental Policy. Agricultural Economics 24, 9-21. 
Kolstad, C.D., 1996. Fundamental Irreversibilities in Stock Externalities. Journal of Public Economics 60(2), 221-233.

Larson, B.A., Frisvold, G.B., 1996. Uncertainty Over Future Environmental Taxes.

Environmental and Resource Economics 8, 461-471.

Lee, J., List, J.A., Strazicich, M.S., 2006. Non-Renewable Resource Prices: Deterministic or Stochastic Trends? Journal of Environmental Economics and Management 51, 354-370.

Maynard, L.J., Shortle, J.S., 2001. Determinants of Cleaner Technology Investments in the U.S. Bleached Kraft Pulp Industry. Land Economics 77(4), 561-576.

McDonald, R., Siegel, D., 1986. The Value of Waiting to Invest. The Quarterly Journal of Economics 101, 707- 727.

Östblom, G. 2007. Nitrogen and Sulphur Outcomes of a Carbon Emissions Target Excluding Traded Allowances - An Input-Output Analysis of the Swedish Case. Working Paper No. 101, National Institute of Economic Research, Stockholm, Sweden.

Pagan, A., 1984. Econometric Issues in the Analysis of Regressions with Generated Regressors. International Economic Review 25(1), 221-247.

Pindyck, R.S., 1999. The Long-Run Evolution of Energy Prices, Energy Journal 20(2), 1-27.

Pindyck, R.S., 2000. Irreversibility and the Timing of Environmental Policy. Resource and Energy Economics 22(3), 233-259.

Pindyck, R.S., 2002. Optimal Timing Problems in Environmental Economics. Journal of Economic Dynamics and Control 26(9/10), 1677-1697.

Postali, F.A.S., Picchetti, P., 2006. Geometric Brownian Motion and Structural Breaks in Oil Prices: A Quantitative Analysis. Energy Economics 28, 506-522.

Purvis, A., Boggess, W.G., Moss, C.B., Holt, J., 1995. Technology Adoption Decisions Under Irreversibility and Uncertainty: An Ex Ante Approach. American Journal of Agricultural Economics 77(August), 541-551. 
Richards, T.J., 1996. Economic Hysteresis and the Effects of Output Regulation. Journal of Agricultural and Resource Economics 21(1), 1-17.

Sarkar, S. 2003. The Effect of Mean Reversion on Investment under Uncertainty. Journal of Economic Dynamics and Control 28, 377-396.

SCB, 2004. Miljöskyddskostnader i industrin 2003. (Environmental Protection Expenditure in Industry 2003), MI 23 SM 0401, Statistics Sweden.

Slade, M.E., 1988. Grade Selection Under Uncertainty: Least Cost Last and other Anomalies. Journal of Environmental Economics and Management 15, 189-205.

Sutherland, R.J., 1991. Market Barriers to Energy Efficiency Investments. The Energy Journal $12(3), 15-34$.

van Soest, D.P., Bulte, E.H., 2001. Does the Energy-Efficiency Paradox Exist? Technological Progress and Uncertainty. Environmental and Resource Economics 18(1), 101-112. 


\section{Tables}

Table 1: Descriptive statistics (at the firm level)

\begin{tabular}{lrrrr}
\hline & Mean & Std. Dev. & Min & Max \\
& & & & \\
$\mathrm{SO}_{2}$ emissions (ktonne/year) & 0.2 & 0.28 & 0.00 & 1.50 \\
Total fuel consumption (TJ/year) & $1,517.6$ & $2,292.9$ & 0.21 & $16,723.5$ \\
Total fuel price (kEUR/TJ) & 7.10 & 3.62 & 1.52 & 17.53 \\
Number of workers & 576 & 555 & 27 & 3,938 \\
Total wages (kEUR/(worker*year) ) & 33.84 & 4.53 & 22.03 & 52.45 \\
Revenue (kEUR/year) & 206,047 & 278,556 & 5,126 & $2,417,918$ \\
& & & & \\
Number of firms & 73 & & & \\
Number of observations & 167 & & & \\
\hline
\end{tabular}

Note: 1 EUR $=9.38942$ SEK, using values from Tuesday, January 8, 2008.

Table 2: Average characteristics of investors and non-investors

\begin{tabular}{lcc}
\hline Variable & Non-investors & Investors \\
& & \\
$\mathrm{SO}_{2}$ emissions (ktonne) & 0.05 & 0.27 \\
Fuel use (TJ/year) & 533 & 1,950 \\
Fuel cost (kEUR/year) & 3,826 & 8,687 \\
Number of workers & 324 & 689 \\
Revenue (kEUR/year) & 76,692 & 262,919 \\
& & 47 \\
Number of firms & 26 & 47 \\
\hline Note: 1 EUR $=9.38942$ SEK, using values from Tuesday, January 8, 2008.
\end{tabular}


Table 3: Estimation results - Comparison of three models ${ }^{(a, b)}$

$\begin{array}{lll}\text { Model } 1 & \text { Model } 2 & \text { Model } 3\end{array}$

Coef. Std. Err. Coef. Std. Err. Coef. Std. Err.

\begin{tabular}{|c|c|c|c|c|c|c|}
\hline \multicolumn{7}{|c|}{ Equation for polluting fuel use (fossil fuel) } \\
\hline Price of labor & 2.2088 & 2.2404 & 0.8323 & 2.0967 & 1.0858 & 1.6533 \\
\hline Price of labor ${ }^{*} 2$ & 0.0055 & 0.0367 & 0.0170 & 0.0366 & & \\
\hline Price of polluting fuel & -9.0969 & 2.5616 & -8.9497 & 2.5884 & -5.9665 & 2.3646 \\
\hline Price of polluting fuel ${ }^{*} 2$ & 0.2046 & 0.0964 & 0.2082 & 0.0975 & & \\
\hline Revenue & 0.0003 & 0.0002 & 0.0003 & 0.0001 & 0.0002 & 0.0001 \\
\hline Revenue*2 $^{*}$ & $-1.12 \mathrm{E}-10$ & $9.91 \mathrm{E}-11$ & $-1.46 \mathrm{E}-10$ & $8.32 \mathrm{E}-11$ & & \\
\hline Number of employees & 1.7813 & 0.9580 & & & & \\
\hline Number of employees $* 2$ & 0.0065 & 0.0037 & & & & \\
\hline CT inv. (pulp and paper) & -0.0109 & 0.0071 & -0.0095 & 0.0071 & -0.0101 & 0.0073 \\
\hline CT inv. (energy sector) & -0.0131 & 0.0043 & -0.0125 & 0.0043 & -0.0123 & 0.0044 \\
\hline EOP inv. (pulp and paper) & -0.0331 & 0.0186 & -0.0374 & 0.0186 & -0.0368 & 0.0190 \\
\hline EOP inv. (energy sector) & 0.0188 & 0.0208 & 0.0223 & 0.0209 & 0.0243 & 0.0214 \\
\hline \multicolumn{7}{|l|}{ Equation for $\mathrm{SO}_{2}$ emissions } \\
\hline Total fuel use & 0.0001 & $5.54 \mathrm{E}-06$ & 0.0001 & $5.53 \mathrm{E}-06$ & 0.0001 & $6.28 \mathrm{E}-06$ \\
\hline Total fuel use*2 & $-1.86 \mathrm{E}-08$ & $2.62 \mathrm{E}-09$ & $-1.89 \mathrm{E}-08$ & $2.57 \mathrm{E}-09$ & & \\
\hline Revenue & 2.33E-08 & $1.79 \mathrm{E}-08$ & $3.27 \mathrm{E}-08$ & $1.55 \mathrm{E}-08$ & $1.59 \mathrm{E}-08$ & $1.42 \mathrm{E}-08$ \\
\hline Revenue*2 $^{*}$ & $-1.12 \mathrm{E}-14$ & $1.09 \mathrm{E}-14$ & $-1.79 \mathrm{E}-14$ & $9.17 \mathrm{E}-15$ & & \\
\hline Number of em & 0.0001 & 0.0001 & 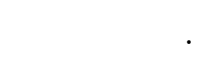 & 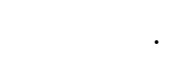 & & \\
\hline Number of employees $* 2$ & $2.21 \mathrm{E}-07$ & $3.99 \mathrm{E}-07$ & & & & \\
\hline CT inv. (pulp and paper) & $-1.22 \mathrm{E}-06$ & $7.72 \mathrm{E}-07$ & $-1.13 \mathrm{E}-06$ & 7.73E-07 & $-8.07 \mathrm{E}-07$ & $9.11 \mathrm{E}-07$ \\
\hline $\mathrm{CT}$ inv. (energy sector) & $7.45 \mathrm{E}-07$ & $4.68 \mathrm{E}-07$ & $7.56 \mathrm{E}-07$ & $4.70 \mathrm{E}-07$ & $8.83 \mathrm{E}-07$ & $5.53 \mathrm{E}-07$ \\
\hline EOP inv. (pulp and paper) & $-3.45 \mathrm{E}-06$ & $2.06 \mathrm{E}-06$ & $-3.90 \mathrm{E}-06$ & $2.04 \mathrm{E}-06$ & $-4.33 \mathrm{E}-06$ & $2.41 \mathrm{E}-06$ \\
\hline EOP inv. (energy sector) & $-8.32 \mathrm{E}-07$ & $2.27 \mathrm{E}-06$ & $-6.70 \mathrm{E}-07$ & $2.28 \mathrm{E}-06$ & $-1.41 \mathrm{E}-06$ & $2.69 \mathrm{E}-06$ \\
\hline
\end{tabular}

Number of observations: 167

(a): CT and EOP stand for Clean Technology and End of Pipe respectively.

(b): Coefficients in bold are significant at the $10 \%$ level. 
Table 4: Direct computation of hurdle rates

$$
\text { Model } 1 \quad \text { Model } 2 \quad \text { Model } 3
$$

Pulp and paper industry (48 observations)

\begin{tabular}{lccc} 
Mean & 3.1045 & 2.6886 & 2.8715 \\
Median & 2.7671 & 2.396 & 2.5594 \\
Minimum & 1.1238 & 0.9732 & 1.0394 \\
Maximum & 8.1306 & 7.0414 & 7.5203 \\
Hurdle rates lower than one & 0 & 1 & 0 \\
\multicolumn{4}{l}{ Energy sector (13 observations) } \\
Mean & 3.6495 & 3.4757 & 3.4158 \\
Median & 3.2794 & 3.1232 & 3.0694 \\
Minimum & 0.8732 & 0.8316 & 0.8173 \\
Maximum & 8.4165 & 8.0155 & 7.8773 \\
Hurdle rates lower than one & 1 & 1 & 1 \\
\hline
\end{tabular}

Table 5: OLS estimation of hurdle rates (61 observations)

\begin{tabular}{|c|c|c|c|c|c|c|}
\hline & \multicolumn{2}{|c|}{ Model 1} & \multicolumn{2}{|c|}{ Model 2} & \multicolumn{2}{|c|}{ Model 3} \\
\hline & Coef. & Std. Err. & Coef. & Std. Err. & Coef. & Std. Err. \\
\hline Pulp and paper industry & 3.1045 & 0.2056 & 2.6886 & 0.1780 & 2.8715 & 0.1901 \\
\hline Energy sector & 3.6495 & 0.4757 & 3.4757 & 0.4530 & 3.4158 & 0.4452 \\
\hline \multicolumn{7}{|l|}{ 95\% Confidence Interval } \\
\hline Pulp and paper industry & \multicolumn{2}{|c|}{$[2.69 ; 3.52]$} & \multicolumn{2}{|c|}{$[2.33 ; 3.04]$} & \multicolumn{2}{|c|}{$[2.49 ; 3.25]$} \\
\hline Energy sector & \multicolumn{2}{|c|}{$[2.70 ; 4.60]$} & \multicolumn{2}{|c|}{$[2.57 ; 4.38]$} & \multicolumn{2}{|c|}{$[2.52 ; 4.31]$} \\
\hline
\end{tabular}


Table 6: Sensitivity tests

\begin{tabular}{lcccccc}
\hline & \multicolumn{2}{c}{ Model 1 } & \multicolumn{2}{c}{ Model 2 } & \multicolumn{2}{c}{ Model 3 } \\
& & & & & \\
& Coef. & Std. Err. & Coef. & Std. Err. & Coef. & Std. Err. \\
\hline & & & & & & \\
& & & & & & \\
Pulp and paper industry & 3.4932 & 0.2313 & 3.0252 & 0.2003 & 3.2310 & 0.2140 \\
Energy sector & 4.1064 & 0.5352 & 3.9108 & 0.5097 & 3.8434 & 0.5009 \\
& & & & & & \\
$\rho=0.190$ & & & & & & \\
Pulp and paper industry & 3.9931 & 0.2644 & 3.4582 & 0.2290 & 3.6934 & 0.2446 \\
Energy sector & 4.6941 & 0.6118 & 4.4704 & 0.5827 & 4.3934 & 0.5726 \\
\hline
\end{tabular}




\section{Appendix}

Derivation of the trigger price for investment under uncertainty (Equation 5 in the text):

The future price of polluting fuel is represented by a geometric Brownian motion with positive drift $\alpha_{m}$ and variance rate $\sigma_{m}$ :

$$
d m=\alpha_{m} m d t+\sigma_{m} m d z_{m} \quad \text { where } d z_{m}=\varepsilon \sqrt{d t}, \varepsilon \sim N(0,1) .
$$

Denote the option value as a function of the fuel price $F(m)$. Let $\rho$ be the firm's discount rate, assumed exogenous here. The Bellman equation is

$$
\rho F(m) d t=E[d F(m)]
$$

which means that, over the interval $d t$, the rate of return of the option to invest should equal the expected rate of its capital appreciation. Applying Ito's Lemma to expand $d F(m)$ gives 1

$$
\frac{1}{2} \sigma_{m}^{2} m^{2} F^{\prime \prime}(m)+\alpha_{m} m F^{\prime}(m)-\rho F(m)=0 .
$$

$F(m)$ should satisfy the above differential equation plus the boundary conditions (A2)-(A4):

$$
F(0)=0
$$

The value of the option is zero when the energy price is zero.

$$
F(\tilde{m})=V(\tilde{m})-I
$$

The value-matching condition: at the trigger price, the value of the option to invest equals the net value of the investment.

$$
F^{\prime}(\tilde{m})=V^{\prime}(\tilde{m})
$$

\footnotetext{
${ }^{1}$ Partial derivatives denoted by a prime.
} 
The smooth-pasting condition: at the trigger price, the change in the value of the option should equal the change in the expected present value of the investment.

Given the boundary conditions, the general solution to the problem can be reduced to the form $F(m)=A_{1} m^{\beta_{1}}$.

The expected present value of the investment at the trigger price is defined as

$$
V(\tilde{m})=\frac{P \triangle y^{*}}{\rho}-\frac{\tilde{m} \triangle a^{*}}{\delta}-\frac{\tau \triangle\left(\gamma a^{*}\right)}{\rho}
$$

where $\delta=\rho-\alpha_{m}$. Equations (A2) to (A5) then imply that

$$
V(\tilde{m})-I=-\frac{\triangle a^{*} \tilde{m}}{\delta \beta_{1}}
$$

where $\beta_{1}$ is the positive root of the fundamental quadratic equation

$$
\frac{1}{2} \sigma_{m}^{2} \beta_{1}\left(\beta_{1}-1\right)+\alpha_{m} \beta_{1}-\rho=0 .
$$

Substituting (A5) into (A6) and rearranging gives the trigger price $\tilde{m}$ :

$$
\tilde{m}=\left(\frac{\beta_{1}}{\beta_{1}-1}\right) \frac{\delta}{\triangle a^{*}}\left(-I+\frac{P \triangle y^{*}}{\rho}-\frac{\tau \triangle\left(\gamma a^{*}\right)}{\rho}\right) .
$$




\section{Derivation of Equation 7:}

The last term in Equation (1) in the text can be rewritten as follows:

$$
-\tau \triangle\left(\gamma a^{*}\right)=-\tau\left[\gamma_{1}-\gamma_{0}\right] a_{1}^{*}-\tau \gamma_{0}\left[a_{1}^{*}-a_{0}^{*}\right]
$$

We then have that $v(m)$, in the notation from the text, can be written as:

$$
v(m)=P \triangle y^{*}-m \triangle a^{*}-\tau \gamma_{0} \triangle a^{*}-\tau \triangle \gamma a_{1}^{*}
$$

where $\triangle \gamma=\gamma_{1}-\gamma_{0}$.

We will focus on the special case of clean technology investments, for which $h_{1}>h_{0}$ but $\gamma_{1}=\gamma_{0}=\bar{\gamma}$, that is abatement investments that increase the efficiency with which a polluting input is used, but does not directly reduce the emission coefficient. Hence, we have $\triangle \gamma=0$, and

$$
v(m)=P \triangle y^{*}-m \triangle a^{*}-\tau \bar{\gamma} \triangle a^{*}
$$

The present discounted value (at the time of the investment, $T$ ) of the increase in profit flows over all future time periods is:

$$
\left.V(m)=\int_{T}^{\infty}\left[P \triangle y^{*}-\left(m_{T}+\bar{\gamma} \tau_{T}\right) e^{\alpha_{m}(t-T)} \triangle a^{*}\right)\right] e^{-\rho(t-T)} d t
$$

where $\rho$ is the appropriate discount rate. The present value can be written

$$
V(m)=\frac{P \triangle y^{*}}{\rho}-\frac{\left(m_{T}+\bar{\gamma} \tau_{T}\right) \triangle a^{*}}{\delta} .
$$

where $\delta=\rho-\alpha_{m}$.

The new trigger price under uncertainty is

$$
\left(m_{T}+\bar{\gamma} \tau_{T}\right)=\left(\frac{\beta_{1}}{\beta_{1}-1}\right) \frac{\delta}{\triangle a^{*}}\left(-I+\frac{P \triangle y^{*}}{\rho}\right) .
$$

